\section{REFERÊNCIAS BIBLIOGRÁFICAS}

01. LESCURA, Y.; MAMEDE, M.V. Educação em Saúde: abordagem para o enfermeiro. São Paulo: Sarvier, 1990.

02. MACEDO, C.G. Discurso pronunciado na cerimônia de abertura. In. $8^{\text {a }}$ Conferência Nacional de Saúde, Anais. Brasília, Ministério da Saúde, 1986.

03. MENDES, I.A.C.; GIR, E.; TREVIZAN, M.A. Escola de Enfermagem de Ribeirão Preto da Universidade de São Paulo: Centro Colaborador da Organização Mundial da Saúde. Rev. LatinoAm. Enfermagem, Ribeirão Preto. v.1, $\mathrm{n}^{\circ}$ especial, p.53-68 dez. 1993.
04. TONES, K.; TILFORD, S.; ROBINSON, Y.K. Health Education: Effectiveness and efficiency, London: Chapman \& Hall, 1991.

05. WORLD HEALTH ORGANIZATION Who Collaborating Centers: general information. Geneva: WHO, 1987. p.12-3.

06. MENDES, I.A.C. Universidade de São Paulo Escola de Enfermagem de Ribeirão Preto/Centro Colaborador OMS para o desenvolvimento de pesquisa em enfermagem. Relatório Anual. fevereiro 1993. Ribeirão Preto, EERP/USP. 43p.

07. MENDES, I.A.C. Carta ao Leitor. Rev. Latino-Am. Enfermagem, Ribeirão Preto, v. 1 n. 1, p. 7-8, janeiro 1993.

\title{
SEMINÁRIO BINACIONAL UNIVERSIDADE FEDERAL DO ACRE E UNIVERSIDAD AMAZÔNICA DE PANDO - ALCANÇA PLENO ÊXITO
}

O Seminário Binacional de Ensino, Pesquisa e Extensão nas Áreas de Biologia, Enfermagem, Pedagogia e Informática, promovido pela Universidade Federal do Acre e Universidad Amazônica de Pando, realizado na cidade de Cobija - Bolívia, e desenvolvido no período de 07 a 09.05.97 foi coroado de pleno êxito tendo em vista a excelente programação, organização e freqüência num total de 191 participantes envolvendo brasileiros de Rio Branco, Brasiléia e Epitaciolândia e Bolivianos de Cobija. Outro ponto relevante foi a troca de experiência nas apresentações, distribuição de material didático-técnico e científico, além das visitas e discussões entre os integrantes dos respectivos cursos/ departamentos/direção das instituições envolvidas Destacamos também a receptividade, repercussão na comunidade acadêmica, bem como as atividades sociais. Cabe ainda mencionar o interesse entre as partes de realizar um novo seminário na Universidade Federal do Acre, para o próximo ano. Como ponto culminante o Reitor da Universidad Amazônica de Pando deverá visitar a Universidade Federal do Acre; os departamentos, coordenações e DERCA se comprometeram em analisar e comparar as grades curriculares já pensando na revalidação dos diplomas, bem como estabelecer protocolos de integração com o aproveitamento de docentes de ambas as partes. 